\title{
Validity of hospital discharge International Classification of Diseases (ICD) codes for identifying patients with hyponatremia
}

\author{
K.L.L. Movig ${ }^{\mathrm{a}, \mathrm{b}}$, H.G.M. Leufkens ${ }^{\mathrm{a}}$, A.W. Lenderink ${ }^{\mathrm{b}}$, A.C.G. Egberts ${ }^{\mathrm{a}, \mathrm{b}, *}$ \\ ${ }^{a}$ Hospital Pharmacy Midden-Brabant, TweeSteden Hospital and St. Elisabeth Hospital, PO Box 90107, 5000 LA, Tilburg, The Netherlands \\ ${ }^{\mathrm{b}}$ Department of Pharmacoepidemiology and Pharmacotherapy, Utrecht Institute for Pharmaceutical Sciences, Utrecht University, \\ Sorbonnelaan 16, PO Box 800823508 TB, Utrecht, The Netherlands
}

Received 20 February 2002; received in revised form 14 November 2002; accepted 16 December 2002

\begin{abstract}
Medical diagnosis can be studied using various sources of information, such as medical and hospital discharge records and laboratory measurements. These sources do not always concur. The objective of the present study was to assess the sensitivity, specificity, and positive and negative predictive values of hospital discharge diagnosis compared with clinical laboratory data for the identification of hyponatremia. Patients with hyponatremia were selected from a hospital information system determined by the International Classification of Diseases, 9th edition (ICD-9). The validity parameters for hyponatremia (ICD code 276.1) were estimated by comparison with accurate serum sodium $\left(\mathrm{Na}^{+}\right)$levels. A total of 2632 cases of hyponatremia were identified using laboratory measurements $\left(\mathrm{Na}^{+} \leqslant 135 \mathrm{mmol} / \mathrm{L}\right)$. The sensitivity of ICD coding for hyponatremia was maximally about $30 \%$ for patients with very severe hyponatremia $\left(\mathrm{Na}^{+} \leqslant 115 \mathrm{mmol} / \mathrm{L}\right)$. Corresponding specificities were high $(>99 \%)$. In $87 \%$ of the cases with severe hyponatremia $\left(\mathrm{Na}^{+} \leqslant 125 \mathrm{mmol} / \mathrm{L}\right)$, other discharge ICD codes reflecting severe morbidity were found. This study suggests that ICD codes for hyponatremia represent only one third of the patients admitted to the hospital and experiencing hyponatremia. About two thirds of the patients with hyponatremia were classified as hospitalized for other reasons. To assess the validity of case finding of patients with hyponatremia, the use of analytical techniques, such as certain laboratory measurements, is advisable. (C) 2003 Elsevier Inc. All rights reserved.
\end{abstract}

Keywords: Hyponatremia; ICD codes; Laboratory values; Record linkage; Sodium

\section{Introduction}

The use of administrative databases for pharmacoepidemiologic research has increased over the past decades [1]. This progress in clinical information management has increased the feasibility for investigating especially low-risk outcomes associated with the use of medicines. In such data sets, drug exposure data originate from prescriptions, or, most often, pharmacy (outpatient) dispensing data and are linked directly using a unique patient identifier or indirectly using probabilistic record linkage with morbidity data from hospital discharge records or general practitioners or other electronic medical data sources $[2,3]$.

Classification and coding systems for drug exposure (e.g., the Anatomical Therapeutic Chemical [ATC] coding system) and morbidity outcomes (e.g., International Classification of Diseases [ICD] codes) provide common language and facilitate the retrieval and analysis of such data. Crucial in

\footnotetext{
* Corresponding author. Tel.: +31-30-2537323; fax: +31-30-2539166.

E-mail address: A.C.G.Egberts@pharm.uu.nl (A.C.G. Egberts).
}

using these data is the validity, which has been studied and discussed extensively [4-7]: In terms of a disease, were all patients within the study domain with a certain outcome retrieved as such (i.e., sensitivity)? and, were all patients classified correctly (i.e., misclassification)? In general, classification in a computerized medical database can be subject to errors, ranging from incomplete reporting by a physician to keypunch mistakes by the coding clerk. Thus, critical considerations should be made when administrative data are used for pharmacoepidemiologic research [8].

Recently, we performed two studies examining the association between the use of antidepressant drugs and the occurrence of hyponatremia, in which two different approaches were used $[9,10]$. First, a case-control study was performed using data from the Dutch PHARMO record linkage database, which contains patients' complete drug-dispensing records obtained from pharmacy files and hospital discharge records [2]. In this study, patients with hyponatremia were identified using hospital discharge diagnosis classified according to the ICD, 9th edition (ICD-9) [9]. Second, in daily clinical practice a study was conducted in which patients 
with hyponatremia were identified using laboratory serum sodium $\left(\mathrm{Na}^{+}\right)$measurements [10]. The results of both studies were consistent and showed an increased risk for hyponatremia due to serotonergic antidepressants in comparison with other antidepressants or nonrecipients of these agents.

$\mathrm{Na}^{+}$measurements are essential to diagnose hyponatremia. In textbooks, hyponatremia is usually defined as $\mathrm{Na}^{+} \leqslant 135 \mathrm{mmol} / \mathrm{L}$ [11]. The clinical symptoms of hyponatremia are variable and depend mainly on its severity and abruptness of onset. Signs and symptoms of hyponatremia generally do not appear until the $\mathrm{Na}^{+}$level falls below 130 $\mathrm{mmol} / \mathrm{L}$. Often, the clinical diagnosis of hyponatremia is missed because of its asymptomatic feature. Hyponatremia can cause significant morbidity, such as lethargy, headache, confusion, convulsions and coma and can occasionally cause death $[12,13]$.

The objective of the present study was to assess the sensitivity, specificity and positive predictive values (PPVs) and negative predictive values (NPVs) of using ICD hospital discharge diagnosis when compared with clinical laboratory data for identifying patients with hyponatremia.

\section{Methods}

\subsection{Setting}

The study was conducted in a 550-bed general teaching hospital that offers in- and outpatient services. The hospital is located in the city of Tilburg, the Netherlands, and covers a population of approximately 170,000 persons. The source population of our study included all patients who had been admitted to this hospital between January 1999 and October 2000.

\subsection{Data sources}

Study subjects were identified using the hospital information system (administrative database) and laboratory $\mathrm{Na}^{+}$ values. In the Tilburg region, all biochemical laboratory data from in- and outpatients are recorded in a centralized database and are available from a single clinical chemistry and hematology laboratory. In the first instance, hyponatremia was defined as a $\mathrm{Na}^{+} \leqslant 135 \mathrm{mmol} / \mathrm{L}$.

The entire hospitalization period, through discharge, was screened for the presence of hyponatremia as registered in the hospital administrative database. A patient was defined as having hyponatremia if the specific ICD-9 code for hyponatremia (276.1) was documented. In the Netherlands, every hospital is compelled to collect diagnostic data on all admissions. This administrative database contains information on patients' demographics, admitting and discharge data, surgical procedures, and discharge diagnosis. The medical record is the basis for the hospital's administrative database. The discharge abstract form (retrieved from the medical record) asks for the principal diagnosis that precipitated the hospital admission. This abstract also lists secondary diagnosis; comorbidities and complications that arise during the hospital stay are commonly included in the secondary diagnosis. The Dutch system allows the registration of up to ten ICD codes per hospital admission. There were no external cause (E) codes for hyponatremia registered in the database. The laboratory data and the hospital administration database include an anonymous unique personal identifier to allow a reliable linkage between information sources. All data were anonymously provided, and the Medical Ethics Committee of the hospital gave its approval to use these data.

\subsection{Data analysis}

$\mathrm{Na}^{+}$measurements were examined in detail and stratified into a nominal scale variable: $\mathrm{Na}^{+} \leqslant 135 \mathrm{mmol} / \mathrm{L}, \mathrm{Na}^{+} \leqslant$ $130 \mathrm{mmol} / \mathrm{L}, \mathrm{Na}^{+} \leqslant 125 \mathrm{mmol} / \mathrm{L}, \mathrm{Na}^{+} \leqslant 120 \mathrm{mmol} / \mathrm{L}$, and $\mathrm{Na}^{+} \leqslant 115 \mathrm{mmol} / \mathrm{L}$. The validity measures for hyponatremia were calculated for each stratum separately using the $\mathrm{Na}^{+}$levels as the comparative reference group because these laboratory measurements are elemental to the diagnosis of hyponatremia. A patient coded as hyponatremic by ICD-9 was considered as a confirmed case of hyponatremia if at least one measurement of blood $\mathrm{Na}^{+}$was performed within the hospital admission period. The hospital admission period was the time between admission and discharge date. The validity measures were based on the outcome of standard $2 \times 2$ tables.

Sensitivity was defined as the probability of hyponatremia based on ICD coding, given true hyponatremia as indicated by laboratory measurements. The percentage of false negative diagnoses was calculated as 1 -sensitivity. Specificity was defined as the probability of not having hyponatremia based on ICD coding, given hyponatremia was truly absent as indicated by laboratory measurements. The PPV was defined as the probability that a patient actually had hyponatremia, given the ICD code for hyponatremia in the hospital discharge data. The NPV was defined as the probability that a patient had no hyponatremia, given absence of the ICD code for hyponatremia.

In addition, logistical regression analysis was used to estimate the probability and to assess the impact of several risk factors for having hyponatremia, given the absence of the ICD code for hyponatremia in the administrative database. Potential risk factors for hyponatremia include age, gender, diabetes mellitus, cardiovascular diseases, hepatic and renal diseases, and thyroid disorders $[9,10,14]$. Univariate correlates for hyponatremia with $P<.05$ were entered into a stepwise multivariate model; the criteria for removal of variables from the equation was set at $P<.10$. The results of the multivariate model were used to calculate probabilities for hyponatremia. The probability was calculated as $1 /\left(1+\mathrm{e}^{-z}\right)$, where $z$ is the sum of the constant and product terms of regression coefficients and variables representing the different risk factors [15]. Every hospital admission was assumed a unique event; thus, the data were analyzed on a 
"per admission" basis. All statistical calculations were carried out with the SPSS statistical package (version 10.0).

\section{Results}

The total number of admissions during the study period was 48,423 from 34,515 patients. The specific ICD-9 code for hyponatremia (276.1) was assigned in 48 of these patients. Thus, searching the hospital's administrative database for hyponatremia on basis of an ICD code would result in a few dozen cases.

Among 12,671 admissions ( $n=12,600$ patients), one or more $\mathrm{Na}^{+}$levels were measured (26\%). Overall, based on clinical chemistry results, a total of 2632 cases were identified with $\mathrm{Na}^{+} \leqslant 135 \mathrm{mmol} / \mathrm{L}$ and were considered to be cases of hyponatremia (Table 1). The sensitivity of ICD9 codes for hyponatremia increased with decreasing cutoff values for blood $\mathrm{Na}^{+}$levels. The sensitivities for cut-off of $\mathrm{Na}^{+} \leqslant 135 \mathrm{mmol} / \mathrm{L}, \mathrm{Na}^{+} \leqslant 130 \mathrm{mmol} / \mathrm{L}, \mathrm{Na}^{+} \leqslant 125 \mathrm{mmol} /$ $\mathrm{L}, \mathrm{Na}^{+} \leqslant 120 \mathrm{mmol} / \mathrm{L}$, and $\mathrm{Na}^{+} \leqslant 115 \mathrm{mmol} / \mathrm{L}$ were $2 \%$, $6 \%, 13 \%, 26 \%$, and $31 \%$, respectively. The specificity was high $(>99 \%)$ for each cut-off value.

In $87 \%$ of the patients validated as severely hyponatremic $\left(\mathrm{Na}^{+} \leqslant 125 \mathrm{mmol} / \mathrm{L}\right)$, other ICD codes were found in the hospital's administrative database. Table 2 presents the

Table 1

Validity measures using laboratory $\mathrm{Na}^{+}$values as reference group for the diagnosis of hyponatremia

\begin{tabular}{|c|c|c|c|c|c|}
\hline & \multicolumn{2}{|c|}{ Hyponatremia } & \multirow[b]{2}{*}{ Total } & & \multirow[b]{2}{*}{ Percentage } \\
\hline & Yes & No & & & \\
\hline \multicolumn{6}{|l|}{$\mathrm{Na}^{+} \leqslant 135 \mathrm{mmol} / \mathrm{L}$} \\
\hline \multirow[t]{2}{*}{$\mathrm{ICD}=276.1$} & 44 & 4 & 48 & Sensitivity & 1.7 \\
\hline & & & & Specificity & $>99.9$ \\
\hline Not $\mathrm{ICD}=276.1$ & 2588 & 10,035 & 12,623 & PPV & 91.7 \\
\hline Total & 2632 & 10,039 & 12,671 & NPV & 79.5 \\
\hline \multicolumn{6}{|c|}{$\mathrm{Na}^{+} \leqslant 130 \mathrm{mmol} / \mathrm{L}$} \\
\hline \multirow[t]{2}{*}{$\mathrm{ICD}=276.1$} & 41 & 7 & 48 & Sensitivity & 6.1 \\
\hline & & & & Specificity & $>99.9$ \\
\hline Not ICD $=276.1$ & 632 & 11,991 & 12,623 & PPV & 85.4 \\
\hline Total & 673 & 11,998 & 12,671 & NPV & 95.0 \\
\hline \multicolumn{6}{|l|}{$\mathrm{Na}^{+} \leqslant 125 \mathrm{mmol} / \mathrm{L}$} \\
\hline \multirow[t]{2}{*}{$\mathrm{ICD}=276.1$} & 27 & 21 & 48 & Sensitivity & 13.4 \\
\hline & & & & Specificity & 99.8 \\
\hline Not ICD $=276.1$ & 174 & 12,449 & 12,623 & PPV & 56.3 \\
\hline Total & 201 & 12,470 & 12,671 & NPV & 98.6 \\
\hline \multicolumn{6}{|l|}{$\mathrm{Na}^{+} \leqslant 120 \mathrm{mmol} / \mathrm{L}$} \\
\hline \multirow[t]{2}{*}{$\mathrm{ICD}=276.1$} & 20 & 28 & 48 & Sensitivity & 26.0 \\
\hline & & & & Specificity & 99.8 \\
\hline Not $\mathrm{ICD}=276.1$ & 57 & 12,449 & 12,623 & PPV & 41.7 \\
\hline Total & 77 & 12,470 & 12,671 & NPV & 99.6 \\
\hline \multicolumn{6}{|l|}{$\mathrm{Na}^{+} \leqslant 115 \mathrm{mmol} / \mathrm{L}$} \\
\hline \multirow[t]{2}{*}{$\mathrm{ICD}=276.1$} & 11 & 37 & 48 & Sensitivity & 30.6 \\
\hline & & & & Specificity & 99.7 \\
\hline Not ICD $=276.1$ & 25 & 12,598 & 12,623 & PPV & 22.9 \\
\hline Total & 36 & 12,635 & 12,671 & NPV & 99.8 \\
\hline
\end{tabular}

Abbreviations: ICD, International Classification of Diseases; PPV, positive predictive value; NPV, negative predictive value. frequencies of the morbidities in patients $(n=174)$ with $\mathrm{Na}^{+} \leqslant 125 \mathrm{mmol} / \mathrm{L}$ without a specific ICD code for hyponatremia. Diabetes mellitus (24\%), heart failure (15\%), and other disorders of fluid, electrolyte, and acid-base balance (12\%) were among the most frequently reported reasons for hospitalization with "hidden" hyponatremia.

When $135 \mathrm{mmol} / \mathrm{L} \mathrm{Na}^{+}$is used as cut-off value for hyponatremia, 4 out of 48 cases were wrongly coded as hyponatremic in the hospital discharge database, which resulted in an overall PPV of $92 \%$ (Table 1). Three out of four patients had increased instead of decreased $\mathrm{Na}^{+}$levels during hospitalization. The PPV for codes specifying hyponatremia decreased as the laboratory cut-off values for hyponatremia were lowered. The NPV was high for each cut-off value.

When univariate variables for hidden hyponatremia were entered into a stepwise logistic regression analysis, the significant correlates for hyponatremia were age, gender, heart failure, emphysema, lung cancer, diabetes mellitus, liver disease, renal disease, hyperkaliemia, and other disorders of fluid, electrolyte, and acid-base balance (Table 3). For example, for a female patient (age 70) without an ICD code for hyponatremia admitted with a diabetic crisis and known

Table 2

Frequencies of hospital discharge codes in patients with $\mathrm{Na}^{+} \leqslant 125$ $\mathrm{mmol} / \mathrm{L}(n=174)$ and $\mathrm{Na}^{+}>125 \mathrm{mmol} / \mathrm{L}(n=12,449)$ but without ICD classification for hyponatremia

\begin{tabular}{|c|c|c|c|}
\hline Morbidity & $\begin{array}{l}\text { ICD-9 } \\
\text { code }\end{array}$ & $\begin{array}{l}\text { Frequency }(\%)^{\mathrm{a}} \\
\leqslant 125 \mathrm{mmol} / \mathrm{L}\end{array}$ & $\begin{array}{l}\text { Frequency }(\%)^{\mathrm{a}} \\
>125 \mathrm{mmol} / \mathrm{L}\end{array}$ \\
\hline \multicolumn{4}{|l|}{ Cardiovascular diseases } \\
\hline Cardiac arrhythmias & 427 & 9 & 7 \\
\hline \multicolumn{4}{|l|}{ Chronic ischemic } \\
\hline heart disease & 413,414 & 5 & 5 \\
\hline Heart failure & 428 & 15 & 8 \\
\hline Hypertension & 401 & 5 & 6 \\
\hline \multicolumn{4}{|l|}{$\mathrm{MI} /$ acute ischemic } \\
\hline heart disease & 410,411 & 10 & 10 \\
\hline \multicolumn{4}{|l|}{ Old myocardial } \\
\hline infarction & 412 & 8 & 8 \\
\hline \multicolumn{4}{|l|}{ Lung diseases } \\
\hline COPD & 496 & 6 & 6 \\
\hline Emphysema & 492,518 & 3 & 2 \\
\hline Lung cancer & 162 & 5 & 2 \\
\hline \multicolumn{4}{|l|}{ Other diseases } \\
\hline Diabetes mellitus & 250 & 24 & 14 \\
\hline Liver disease & $570-573$ & 6 & 2 \\
\hline Renal disease & $582-590$ & 6 & 4 \\
\hline Hyperkalemia & 276.7 & 2 & $<1$ \\
\hline $\begin{array}{l}\text { Other disorders of flu } \\
\text { electrolyte and } \\
\text { acid-base balance }\end{array}$ & $\begin{array}{c}276 \\
(\operatorname{not} 276.1, \\
276.7)\end{array}$ & 12 & 2 \\
\hline $\begin{array}{l}\text { Hypo/hyperthyroid } \\
\text { disease }\end{array}$ & $240-246$ & 7 & 4 \\
\hline
\end{tabular}

Abbreviations: ICD-9, International Classification of Diseases, 9th edition; MI, myocardial infarction; COPD, chronic obstructive pulmonary disease.

${ }^{a}$ Numbers do not add up to $100 \%$ because patients were frequently assigned more than one discharge diagnosis. 
Table 3

Logistic regression variables as predictors for hidden hyponatremia defined as $\mathrm{Na}^{+}$cut-off $\leqslant 125 \mathrm{mmol} / \mathrm{L}$

\begin{tabular}{lrllll}
\hline Variables $^{\mathrm{a}}$ & \multicolumn{1}{c}{$\boldsymbol{\beta}$} & $\mathrm{SE}$ & $\mathrm{OR}$ & $95 \% \mathrm{CI}$ & $\begin{array}{l}\text { Probability } \\
(\%)\end{array}$ \\
\hline Intercept & -1.911 & 0.071 & & & 13 \\
Age (per year) & 0.004 & 0.001 & 1.004 & $1.002-1.006$ & \\
Gender (women) & 0.174 & 0.045 & 1.19 & $1.09-1.30$ & 50 \\
Heart failure & 0.465 & 0.075 & 1.59 & $1.38-1.85$ & 61 \\
Emphysema & 0.752 & 0.144 & 2.12 & $1.60-2.81$ & 68 \\
Lung cancer & 0.719 & 0.144 & 2.05 & $1.55-2.72$ & 67 \\
Diabetes mellitus & 0.398 & 0.060 & 1.49 & $1.32-1.67$ & 60 \\
Liver disease & 1.097 & 0.122 & 3.00 & $2.36-3.80$ & 75 \\
Renal disease & 0.317 & 0.112 & 1.37 & $1.10-1.71$ & 58 \\
Hyperkalemia & 1.894 & 0.548 & 6.65 & $2.27-19.4$ & 87 \\
Other disorders of & & & & & \\
$\quad$ fluid, electrolyte, & & & & & \\
$\quad$ and acid-base & & & & & \\
$\quad$ balance & 0.840 & 0.123 & 2.32 & $1.82-2.95$ & 70 \\
\hline
\end{tabular}

Abbreviations: SE, standard error; OR, odds ratio; CI, confidence interval.

${ }^{a}$ Not selected in the stepwise logistic model: cardiac arrhythmias, chronic ischemic heart disease, hypertension, myocardial infarction, chronic obstructive pulmonary disease, hypo/hyperthyroid disease.

to have liver disease, the predicted probability for having hyponatremia was $53 \%$. In the absence of any variable, the probability for hyponatremia was about $13 \%$.

\section{Discussion}

The validity of using ICD codes for identifying cases with hyponatremia in hospitalized patients as presented in this study warrants careful weighing of the pros and cons of such data sources. Administrative data have clear advantages in terms of availability, cost-effectiveness, and large numbers. However, the data in this study show that using the specific ICD code for hyponatremia may lead to serious underestimates; the same is valid for other symptoms of severe morbidities (e.g., cardiac arrhythmias in patients with severe heart failure [16] and acid-base disturbances in patients with specific types of cancer [17]). One may argue that such concomitant clinical features hidden by more severe morbidity are probably more related to the underlying disease and are rarely drug induced. However, one should also take into account that the inability to identify the large majority of cases of a specific outcome, in this study hyponatremia, may lead to bias in case-control studies when controls are sampled from the source population and include a significant number of hidden patients with hyponatremia.

In this study, approximately $87 \%$ (174/201) of the patients with serious hyponatremia $(\leqslant 125 \mathrm{mmol} / \mathrm{L})$ were not coded as such in the hospital discharge database, and $94 \%$ of all patients with $\mathrm{Na}^{+} \leqslant 130 \mathrm{mmol} / \mathrm{L}$ were not labeled accordingly. Overall, the sensitivity increased with lowering the laboratory cut-off values for hyponatremia. When we used more strict criteria for hyponatremia, the sensitivity increased to about $30 \%$. The specificity was uniformly high in all strata. The PPV for the ICD code used to identify cases with hyponatremia was $92 \%$ when using a cut-off of $135 \mathrm{mmol} / \mathrm{L}$.

According to the multivariate model, about $13 \%$ of all hospitalized patients are expected to have hyponatremia irrespective of other variables, which corresponds with frequencies cited in the literature $[18,19]$. The probability for hyponatremia in patients not labeled as such increases in patients having one or more risk factors for hyponatremia. This finding confirms the suggestion that hyponatremia is hidden under a more serious and recognized clinical situation.

Previous data comparing hospital administrative data with raw laboratory data are rare. Studies comparing medical records with hospital administrative data have been conducted but are often inconsistent. The validity measurements using ICD codes for identifying diagnostic information were assessed in previous studies [5,6,20-22]. For complicated peptic ulcer disease, Raiford et al. found high levels of accuracy (PPV 90\%) comparing hospital medical records with ICD codes from an administrative database [20]. Comparable results were found by Cattaruzzi et al. [21]. McCarthy et al. determined whether clinical evidence was found in medical records for medical complications coded by ICD [22]. Their study showed that administrative data overestimated the presence of certain medical conditions. Overall, it was found that no documented evidence was available for $20 \%$ to $30 \%$ of all ICD codes in patients' files.

In the present study, we found that the rates of confirmatory laboratory evidence for hyponatremia varied widely over the different strata. One potential explanation for our findings is that in everyday clinical practice, hyponatremia is difficult to diagnose by means of physical examination and is not always considered [23]. Another possible explanation is that sodium laboratory tests were routinely recorded in a selected patient population with other severe comorbidities. In that situation, the diagnostic labeling process might be biased. In general, patients with a mild form of a condition are not recorded accordingly if the administrative database records only more severe comorbidities. The Dutch system allows registration up to ten clinical manifestations, but a previous study has shown that an increased number of registration positions on the discharge abstract form does not necessarily improve coding completeness [4]. A physician can introduce differential under-reporting when only the most severe clinical situations are coded. Previous researchers found that severity of illness and complications take precedence in coding over chronic comorbid conditions $[4,24]$. Serious risk factors for hyponatremia were frequently reported in patients that were not labeled as hyponatremia (Table 2). This finding supports the possibility that some comorbidities are judged more important than others in the coding process. In this study, even in patients with a potentially fatal condition of hyponatremia $\left(\mathrm{Na}^{+} \leqslant 115\right.$ $\mathrm{mmol} / \mathrm{L}$ ), only about $30 \%$ had been recorded correctly as hyponatremic. 


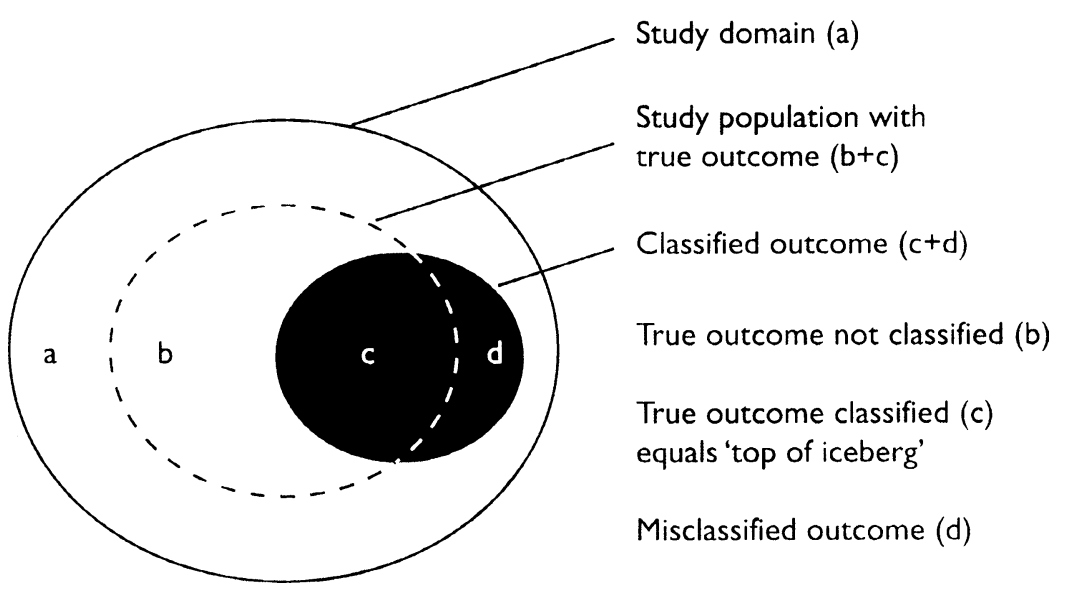

Fig. 1. "Tip of the iceberg" principle.

The generalizability of the data should be taken into account. This study was performed using data from only one hospital, so the results may not be generalizable to other services or settings. Furthermore, the results of this study are not necessarily transferable to other types of medical problems. The ability of administrative databases to identify patients' diagnoses may be different for other types of medical situations. A key advantage of our study is the fact that we had access to accurate laboratory measurements-false positive classification by ICD coding is restricted when laboratory values are used. The use of abnormal laboratory results as an adverse drug reaction (ADR) indicator would potentially identify two thirds of all adverse drug reactions [25]. From this point of view, the use of clinical laboratory data as reference data is preferable to ICD codes studying ADRs or other clinical events. The large number of cases for which laboratory and administrative data were available and comparable favors the results of our study.

The results in this study raise important considerations for researchers using computerized medical databases or laboratory data to identify patient outcomes in an epidemiologic study. First, the principal of the "tip of the iceberg," which is familiar within cases of spontaneous reporting, should be taken into account. It is not unlikely that only a small proportion of hyponatremic cases was detected and coded. This concept is explored further in Fig. 1: When area $c$ becomes relatively small, sample size issues can become problematic in designing a (pharmaco) epidemiologic study. However, administrative databases are often large enough to provide adequate population sizes for measuring drug exposure and rare medical events [26]. Second, a key advantage of using centralized clinical chemical laboratory data is that the population under study can be well defined and enumerated. Laboratory data facilitates the identification of all the cases occurring in the population, which directly reduces the likelihood of selection bias. However, in the case of hyponatremia, it is not unlikely that only the most severe cases were referred to the hospital and identified as hyponatremic and recorded accordingly. In that case, the use of administrative data based on discharge codes also underestimates the presence of hyponatremia by recording only the most severe cases. Irrespective of the use of centralized laboratory data, selection bias may still be a concern because of the bias associated with referral for laboratorium tests in general and serum sodium tests in particular. Selection of patients (referral bias) should be taken into account when assessing the prevalences of comorbidities by the use of hospital administrative databases that supply hospital discharge codes only.

In summary, we found that ICD codes are highly specific for hyponatremia but are not very sensitive. The completeness of hospital discharge ICD codes for hyponatremia may lead to an underestimate of the prevalence estimate. From this point of view, the use of administrative data only for the detection of clinically relevant patient outcomes (e.g., adverse drug effects) also occurring as concomitant clinical feature in patients with severe morbidity comprises important limitations. Thus, analytical laboratory measurements obtained in daily clinical practice are of important additive value in pharmacoepidemiologic studies investigating infrequent (adverse) effects.

\section{References}

[1] Strom BL. Data validity in using claims data. Pharmacoepidemiol Drug Saf 2001;10:389-92.

[2] Herings RM, Bakker A, Stricker BH, et al. Pharmaco-morbidity linkage: a feasibility study comparing morbidity in two pharmacy based exposure cohorts. J Epidemiol Community Health 1992;46:136-40.

[3] Lau HS, de Boer A, Beuning KS, et al. Validation of pharmacy records in drug exposure assessment. J Clin Epidemiol 1997;50:619-25.

[4] Iezzoni LI, Foley SM, Daley J, et al. Comorbidities, complications, and coding bias: does the number of diagnosis codes matter in predicting in-hospital mortality? JAMA 1992;267:2197-203.

[5] Romano PS, Roos LL, Luft HS, et al. A comparison of administrative versus clinical data: coronary artery bypass surgery as an example. Ischemic Heart Disease Patient Outcomes Research Team. J Clin Epidemiol 1994;47:249-60. 
[6] Geraci JM, Ashton CM, Kuykendall DH, et al. International Classification of Diseases, 9th Revision: clinical modification codes in discharge abstracts are poor measures of complication occurrence in medical inpatients. Med Care 1997;35:589-602.

[7] West SL, Strom BL, Poole C. Validity of pharmacoepidemiological drug and diagnosis data. In: Strom BL, editor. Pharmacoepidemiology. Chichester: John Wiley \& Sons; 2000. p. 661-705.

[8] Iezzoni LI. Using administrative diagnostic data to assess the quality of hospital care: pitfalls and potential of ICD-9-CM. Int J Technol Assess Health Care 1990;6:272-81.

[9] Movig KL, Leufkens HG, Lenderink AW, et al. Serotonergic antidepressants associated with an increased risk for hyponatraemia in the elderly. Eur J Clin Pharmacol 2002;58:143-8.

[10] Movig KL, Leufkens HG, Lenderink AW, et al. Association between antidepressant drug use and hyponatraemia: a case-control study. $\mathrm{Br}$ J Clin Pharmacol 2002;53:363-9.

[11] Reeves WB, Buchet DG, Andreoli TE. Posterior pituitary and water metabolism. In: Wilson J, Foster D, editors. Williams textbook of endocrinology. Philadelphia: WB Saunders; 1998. p. 341-87.

[12] Singer GG, Brenner BM. Fluids and electrolytes. In: Braunwald E, Fauci AS, Kasper DL, Hauser SL, Longo DL, Jameson JL, editors. Harrison's principles of internal medicine. New York: McGraw-Hill; 2001. p. 271-83.

[13] Kumar S, Berl T. Sodium. Lancet 1998;352:220-8.

[14] Siegler EL, Tamres D, Berlin JA, et al. Risk factors for the development of hyponatremia in psychiatric patients. Arch Intern Med 1995;155:953-7.

[15] Hennekens CH, Buring JE. Epidemiology in medicine. Boston/Toronto: Little, Brown and Compagy; 1987.

[16] Bouvy ML, Heerdink ER, De Bruin ML, et al. Use of sympathomimetic drugs leads to increased risk of hospitalization for arrhythmias in patients with congestive heart failure. Arch Intern Med 2000; 160:2477-80.

[17] Milionis HJ, Bourantas CL, Siamopoulos KC, et al. Acid-base and electrolyte abnormalities in patients with acute leukemia. Am J Hematol 1999;62:201-7.

[18] Flear CT, Gill GV, Burn J. Hyponatraemia: mechanisms and management. Lancet 1981;2:26-31.

[19] Gill G, Leese G. Hyponatremia: biochemical and clinical perspectives. Postgrad Med J 1998;74:516-23.

[20] Raiford DS, Perez Gutthann S, Garcia Rodriguez LA. Positive predictive value of ICD-9 codes in the identification of cases of complicated peptic ulcer disease in the Saskatchewan hospital automated database. Epidemiology 1996;7:101-4.

[21] Cattaruzzi C, Troncon MG, Agostinis L, et al. Positive predictive value of ICD-9th codes for upper gastrointestinal bleeding and perforation in the Sistema Informativo Sanitario Regionale database. J Clin Epidemiol 1999;52:499-502.

[22] McCarthy EP, Iezzoni LI, Davis RB, et al. Does clinical evidence support ICD-9-CM diagnosis coding of complications? Med Care 2000;38:868-76.

[23] Miller M, Hecker MS, Friedlander D, et al. Apparent idiopathic hyponatremia in an ambulatory geriatric population. J Am Geriatr Soc 1996;44:404-8

[24] Powell H, Lim LL, Heller RF. Accuracy of administrative data to assess comorbidity in patients with heart disease: an Australian perspective. J Clin Epidemiol 2001;54:687-93.

[25] Tegeder I, Levy M, Muth-Selbach U, et al. Retrospective analysis of the frequency and recognition of adverse drug reactions by means of automatically recorded laboratory signals. Br J Clin Pharmacol 1999;47:557-64.

[26] Bright RA, Avorn J, Everitt DE. Medicaid data as a resource for epidemiologic studies: strengths and limitations. J Clin Epidemiol 1989; 42:937-45. 